\title{
Information Resources Management for Customer Focus in Small Manufacturing Companies
}

\author{
Peter Sackett and Valerie Ratcliffe-Martin \\ CIM Institute \\ Cranfield University \\ MK43 OAL \\ Cranfield, Bedford \\ United Kingdom \\ Tel: 01234754073 \\ Fax: 01234750852 \\ Email:V.Martin@cranfield.ac.uk
}

\begin{abstract}
This paper covers a recent pilot study undertaken in a small manufacturing company. The purpose was to identify the information resources which the company required to be Customer-Focused, and to test whether the methodology used is appropriate. The reasons why Customer-Focus in small companies is considered a relevant area and why the particular methodology was selected are explained, and the results and further discussion are presented.
\end{abstract}

\section{Keywords}

Information Resource Management, Customer-Focus, Small Manufacturing Companies 


\section{INTRODUCTION}

Recent work in manufacturing companies has shown that there is a link between the effective utilisation of information and customer satisfaction. Little is known about what this information should be or how it should be managed. This paper reports on a current research project which explores the information resources which enable a small manufacturing company to be customer-focused. ${ }^{1}$

The authors describe the results of an initial pilot study undertaken in a small manufacturing company. An established methodology for Information Resources Management is used. The pilot study evaluates the methodology as a tool for exploring these information resources.

\section{INFORMATION RESOURCES MANAGEMENT}

\subsection{Development}

The study of information in organisations is often fragmented - it tends to be associated with information technology (Ward 1995, Earl 1989, Knight and Silk 1990). Rarely does this capture the richness and interest of the variety of information used in most organisations - paper-based, verbal, formal and informal.

The concept of information as a resource has evolved in recent years (Horton 1980, CCTA 1990, Beaumont and Sutherland 1992, Synott 1981, Willard 1993, Orna 1996) and it is now based on the idea that information in the wider sense as described above can be managed and utilised for strategic advantage in the same way as man, material and money - it has been called the 'Fourth Resource' (Best 1996).

\subsection{Burke and Horton}

Burke and Hortons 'Infomap' (1988) approach to Information Resources Management was selected as a tool for this evaluation as it provides an established methodology. It provides a structured methodology to identify and value information resources.

The Burke and Horton methodology claims to identify, cost, value and generally enable an organisation to gain an overview of its information resources through a four stage process:

\footnotetext{
${ }^{1}$ A small manufacturing company is defined here as one which has less than 50 employees
} 
- Stage 1. - The Preliminary Inventory: background knowledge of company, identify users, managers and handlers of information, systems, services and sources.

- Stage 2. - Costing and Valuing the Information Resource Entities: perceptions can be gathered on: quality of information, utility of information holdings, impact on productivity, effectiveness and financial position.

- Stage 3. - Information Resource Mapping Techniques: the Information Resource Elements are mapped on a grid to present this array of data.

- Stage 4. - The Corporate Information Resource: the previous steps combine to form a detailed picture of the company information resources - their strengths, weaknesses, purpose, accessibility, managers, users, characteristic, strategic value etc.

A valuable aspect of this four-step approach is identifying hidden resources - this generally pertains to the informal, more tacit types of information which is so important and often goes unrecognised (Burke and Horton 1988). In small companies in particular, customer interaction is frequently unstructured, unplanned, even invisible.

\section{SMALL MANUFACTURING COMPANIES AND THEIR CUSTOMERS}

\subsection{Competition and Uncertainty}

Small manufacturing companies are under pressure from Market Drift (Puttick and Gillis 1995). The rapid development of sophisticated short life products has made competition harder to beat and the satisfaction of customers harder to accomplish. This places small companies in a highly uncertain environment. Small companies are also at risk as their customers reduce their supplier base. For many of these small companies the best use of their resources is to develop better relationships with their own existing customers.

\subsection{Customer-Focus}

Christopher and McDonald suggest that customer service is not only about the immediate order-to-invoice cycle - it concerns three elements (1995) :

1. pre-transaction elements (strategic policy to customers, organisational structure and flexibility)

2. transaction elements (the immediate order-to-invoice cycle)

3. post-transaction elements (after-sales service, customer complaints)

Customer-focus is the ability of the organisation to utilise its resources to concentrate on customers in a proactive manner for the purposes of providing 
immediate satisfaction and building confidence and loyalty. Harnessing information resources is an innovative and alternative way to achieve this.

Banks and Stone have already cited the lack of information utilisation in this area (1995). There is a void between the level of reliance on loyal customers, the ability to retain customers, and the use of information resources.

\section{PILOT STUDY}

We tested the Burke and Horton methodology in a small manufacturing company of 30 employees, which has followed the marketplace - some of its main customers from the computer industry. It has developed and updated its technology and skills level to combat market drift and offer a sophisticated product. It demonstrates a high awareness of Customer-Focus - its mission statement is customer-focused, it carries out customer surveys, relationship marketing, is BSI registered, is working towards EFQM, has a customer-focused business plan, and has also been customer oriented in its strategy in that it has followed the demands of its most important customers.

We aimed to:

- Explore how this small manufacturing company translates customer-focus into its manufacturng strategy, and how it uses information to do so. A Case Study methodology was decided on to gather background data on the context of the organisation.

- Describe the Information Resource Entities - what they are, where they are in the organisation, and how valuable they are. A survey was used to gather perceptions on the value of the Information Resource Entities which is relative to Customer-Focus

DATA COLLECTION

The case study included:

- 6 semi-structured interviews with key people

- examination of documents, including business plan, customer order documentation, computer prints outs, quality manuals, specifications

The interviews set the scene, and identified as many potential information resource entities as possible for the preliminary inventory. They were structured in four parts -

- background information, culture and subcultures

- language and general understanding between functions

- formal processes for customer satisfaction 
- software, hardware and paper-based information

This structure is supported by literature in the area of information and customer satisfaction in manufacturing - Hill (1994) claims that information is a crucial element in linking functions to marketing to provide customer satisfaction on three levels: functional perspectives, customer order documentation, customer viewpoints.

The Christopher and McDonald model complements this by exploring strategic policy to customers and company background. Therefore, functional perspectives were elicited from questions on culture and language used, actual customer order documentation was elicited from questions on processes and electronic and paper based information. The customer viewpoint was taken as the information given by them when the order arrived, or through pre-order alerts.

We found that interviewees had difficulty in answering specific questions regarding information resources. Therefore we decided to observe to capture the information which is more intangible. This included talk throughs, management meetings, customer order trail and job trails.

\section{ANALYSIS OF DATA}

The methodology has identified lists of potential information resource entities in the company. However, there are two basic drawbacks in regard to customerfocus.

\subsection{The methodology is long and complex}

In the pilot study we only had time to focus on the first step of the methodology, out of the four. Unless all the important information is elicited at the first step, there is no point in going further and Burke and Horton themselves confirm that this is the most important step. The methodology also cannot be carried out easily in a linear fashion, as suggested.

\subsection{The methodology is too simplified}

Although this sounds contradictory to the above, the methodology, through its complexity, actually tries to simplify the organisation. It attempts to deconstruct the organisation and can lose the richness and the dynamics which may be vital in this particular context for customer satisfaction. For example:

The Classification Structure: It is difficult to distinguish between users, handlers and managers of information, and information sources, services and systems, which form part of the classification scheme in the methodology. Examples: 
- The BSI manual is managed, handled and used by the Projects co-ordinator, and the Job Card on the shopfloor is managed, handled and used by the distribution Manager, Sales, Production Manager, and most of the engineers.

People: People also count as potential resources - it is difficult to separate people from information. They not only use, handle and manage it, they also create it, and use the information for different purposes. The methodology treats the information as 'static', assuming it always resides in the same place, with the same people for the same purposes. It does not view the resources as an integrated system. Examples:

- A technical evaluation is information on how to proceed for the shopfloor manager, but for the sales manager it forms the basis of a quote. This information, although on paper, often needs further negotiation and changes during the life cycle of the customer order. It cannot be recorded in detail on the Inventory Data Form - it is too transient, informal and changing.

Relationships: Not only individual people, but relationships between them are an important 'hidden' information resource. Data was best gathered through observation. Much of the information important for customer satisfaction in the company is difficult to capture and identify clearly - it is informal and dynamic. Even more so the many face to face encounters, telephone calls and impromptu meetings that happen every day.

\section{INFORMATION RESOURCE MANAGEMENT - A HELP OR A HINDRANCE?}

The idea of Information Resource Management is feasible. The methodology describes a basis for identifying information resource requirements in an industrial environment. In the company concerned, there is nothing which is not affected by information and this was illustrated by the Burke and Horton approach. Even the parts which are brought in for repair are in themselves a source of information - sales use them to give an idea of the quote, engineers assess them to see what is wrong with them. Information is a valuable resource for Customer Focus in this company.

However, the Burke and Horton approach has the drawbacks as stated above - it is long and elaborate, and does not capture all the richness of important peoplebased information. It is not a systemic approach - it attempts to reduce all information in the organisation to tiny parts. This is suggestive of the methaphor of the organisation as a 'machine' - embodied through Scientific Management (Taylor).

The Burke and Horton approach, though going beyond the sheer technical, fragmented aspect, is still a further development of this metaphor. Flood and Jackson (1991) claim the machine paradigm is useful when:

- the task to be performed is straightforward

- there is repetitive production of a single product 
- the 'human parts' fit into the design and follow machine-like commands

- in a stable environment

and breaks down when

- it reduces the adaptability of the organisation (i.e. a machine-like organisation is vulnerable in a volatile environment)

- it requires a mindless contribution that is difficult to maintain with mindful parts (i.e. it will either dehumanise or will lead to conflicting aims between machine and minds)

The Burke and Horton methodology would probably work very well in a company which fits the machine metaphor. The Company concerned in this study does not support a machine-like structure - it does not require a mindless contribution, and has proven to be adaptable to its environment. It is a system, with open boundaries with its customers and the rest of the business environment. It is synergistic, hierarchical and has richly interactive elements and relationships.

It is also a complex system - the company has many different customers, about 140 in total. This is a significant factor in why the Burke and Horton model does not go far enough to explain Customer-Focus in this particular case - the complexity in the transaction elements themselves give rise to the rich information in the Company. Therefore, the company is highly informationintensive.

\section{DISCUSSION}

The Burke and Horton approach has not entirely worked in this particular case study for the reasons above. To expand it, a systems approach may be required. However, Holtham claims that applications of systems concepts have largely been unsuccessful in the past, and questions whether information management will ever be a coherent and eclectic discipline (1996).

Systems approaches have been badly understood by those implementing them during the decades of more stable products and markets there was less need to. Now things are different - the increasing complexity and uncertainty in which small companies operate may mean eventually that the information resource will have to be recognised for what it appears to be - a highly systemic phenomenon. This research project will go on to explore ways in which this can be done.

\section{REFERENCES}

Banks, J. M. and Stone, C. L. (1995) Improving Business Performance ThroughCustomers and Employees - The Results of a Survey of the Times Top 500 The Total Quality and Innovation Management Centre, 
Anglia Polytechnic University.

Beaumont, J. and Sutherland, E. (1992) Information Resources

Management. Butterworth-Heinemann.

Best, D. (1996) The Fourth Resource. ASLIB/Gower.

Burke, C. F. and Horton, F. W. (1988) Infomap: a Complete

Guide to Discovering Corporate Information Resources.

Englewood Cliffs:Prentice-Hall.

CCTA (1990) Managing Information as a Resource.London HMSO.

Christopher, M. and Mc Donald, M. (1995) Marketing - An

Introductory Text. MacMillan Business.

Earl, M. (1989) Management Strategies for Information Technology.

Prentice Hall, Englewood Cliffs.

Flood, F. and Jackson, M. (1991) Creative Problem Solving. Wiley.

Hill, T. (1994) Manufacturing Strategy. Irwin.

Horton, F. W. (1980) Information Resources Management. Prentice Hall.

Holtham, C. (1996) Resolving the Imbalance Between Information

and Technology, in The Fourth Resource (ed. D. Best), ASLIB/Gower.

Knight, A.V. and Silk, D. J. (1980) Managing Information - Information

Systems for Today's General Manager. McGraw Hill.

Orna, E. (1996) Valuing Information:Problems and Opportunities,

in The Fourth Resource (ed. D. Best), ASLIB/Gower.

Puttick, J. and Gillis, J. (1995) Factory for the Future. Synopsis of Final Report.

Taylor, F.W. (1947) Scientific Management. Harper and Row, London

Ward, J. (1995) Principles of Information Management. Routledge.

Willard, N. (1993) Information Resources Management. ASLIB Information, May 1993.

\section{BIOGRAPHIES}

Peter Sackett holds degrees from UMIST, UK. Following an engineering apprenticeship at Rolls Royce Aero Engines, he worked in Aerospace Equipment, and Heavy Automotive. Work with IBM Trust led to the founding of The CIM Institute at Cranfield University. He was appointed Director of Academic Programmes in The CIM Institute, 1987, and Professor of Integrated Systems in 1990. In 1996 he was appointed Head of Department, CIM Institute.

Valerie Ratcliffe-Martin began her career as an international musician, gaining degrees in music and working abroad. She then returned to the UK where she gained an M.Sc in Information Management. She went on to work at Sheffield Business School as a researcher in Manufacturing Change, and a lecturer in Information Management and Organisational Behaviour. In 1996 she was appointed to run Learning Clusters for manufacturing companies on the Bedfordshire ADAPT/CORE programme at Cranfield University and is also currently working towards a Ph.D. 